\title{
What is the value of neonatal autopsy? Pathological and clinical correlation in $\mathbf{1 3 5}$ cases
}

\author{
Fernanda Tamanaha, M.D. ${ }^{a}$, Rosa Fuksman, M.D. ${ }^{a}$, Ana Pedraza, M.D. ${ }^{a}$ and Luis Prudent, M.D. ${ }^{a}$
}

\begin{abstract}
Introduction. Neonatal autopsy is a valuable, critical diagnostic method to provide genetic counseling for future pregnancies. Population and methods. Retrospective study including all neonatal autopsies performed on deceased neonates at Clínica y Maternidad Suizo Argentina between January 1998 and December 2006. The rate of autopsies was established; the diagnosis indicated in the medical record was compared to autopsy findings.

Results. Out of 227 deceased infants, 135 autopsies were performed (rate: $59.5 \%$ ). Concordance was complete in $25 \%$ of autopsies. New information was found in $26 \%$, which had significant implications for genetic counseling.

Conclusions. The rate of autopsies was 59.5\%. Pathological and clinical correlation and unsuspected findings with implications for genetic counseling demonstrate the relevance of performing neonatal autopsies systematically.

Key words: autopsy, newborn infant, rate, pathological and clinical correlation, genetic counseling.

http:/ / dx.doi.org/10.5546/ aap.2017.eng.490
\end{abstract}

To cite: Tamanaha F, Fuksman R, Pedraza A, et al. What is the value of neonatal autopsy? Pathological and clinical correlation in 135 cases. Arch Argent Pediatr 2017;115(5):490-493.

\section{INTRODUCTION}

Autopsy has been used as a diagnostic method since the $15^{\text {th }}$ century and has played a critical role in medical advances. It is particularly valuable in the neonatal period because in addition to providing objective information on the cause of death, it allows -in the face of many unexpected findings- to provide adequate counseling with direct implications for future family planning.

a. Division of Neonatology, Clínica y Maternidad Suizo Argentina, Autonomous City of Buenos Aires.

E-mail address:

Fernanda Tamanaha, M.D.: fernanda.tamanaha@gmail.com

Funding: None.

Conflict of interest: None.

Received: 7-5-2016

Accepted: 3-22-2017
In spite of their undeniable relevance, the use of autopsies started to decline considerably worldwide as of the 1970s, ${ }^{1,2}$ either on newborn infants, children, or adults. In Argentina, publications on the number of autopsies performed on newborn infants confirm such marked decline.,

\section{OBJECTIVES}

To establish the prevalence of autopsies and analyze the correlation between clinical diagnosis and anatomopathological findings.

\section{POPULATION AND METHODS}

This was a retrospective and observational study including all autopsies performed on deceased newborn infants at the Division of Neonatology of Clínica y Maternidad Suizo Argentina over a 9-year period (January 1998 to December 2006). The study was approved by the hospital's Research Ethics Committee.

Parents were asked to authorize the autopsy by staff physicians, coordinators or heads of the Division of Neonatology. They explained the study relevance, what the procedure included, and how long it would take so that parents could make burial arrangements. In addition, parents were asked to sign an informed consent.

All autopsies were performed by the same perinatal pathologist and her team. A karyotype test was done, and whole body $\mathrm{X}$-ray images and external photos were taken in all cases.

External examination, anthropometric profile, and evisceration were done within 48 hours of death, and macro- and microscopic examinations were done on all organs. Grand rounds were conducted to discuss pathological and clinical findings of 101/ $135(75 \%)$ cases.

Autopsy results were reported to the parents during meetings with the treating neonatologists in the two months following their child's death.

The diagnosis obtained from the medical record was compared to that made during the autopsy using Goldman's classification as modified by Kumar ${ }^{5,6}$ (Table 1).

The initial categorization was made by one of the authors (FT), who discussed the diagnosis with two other neonatologists in case of doubts 
(27 cases). When doubts were raised in relation to the interpretation of anatomopathological reports, these were discussed with the pathologist (RF).

The rate of autopsies was estimated based on the total number of deaths occurred over the study period.

\section{RESULTS}

A total of 135 autopsies were performed out of 227 neonatal deaths occurred in the study period, resulting in a rate of $59.5 \%$. Figure 1 shows the rates of autopsy by year in the 1998-2006 period. The analysis of pathological and clinical correlation showed the following:

- Concordance was complete in $25 \%$ of cases $(34 / 135)$ (class V), and partial in $75 \%$ of cases (101/135) (classes I, II, III, IV).

- Diagnosis made based on the autopsy helped to provide an adequate genetic counseling in $26 \%$ of cases (class I.B).

- An anatomopathological diagnosis would not have modified treatment if detected in life in $24.4 \%$ of cases (class II).

- Anatomopathological findings had not been diagnosed in $15 \%$ of cases, although detection in life would not have modified the disease process because it was a condition that could not be cured (class III).

- Autopsy findings in $6.6 \%$ of cases indicated that diagnosis in life would have modified the child's therapeutic approach and, probably, disease course (class I.A).

- Diagnosis was not related to the clinical process in $3 \%$ of cases, making it uncertain to establish if it may or may have not affected the eventual outcome of the patient (class IV). Pathologies that could have been managed with a different therapeutic approach in class I.A included pulmonary candidiasis and perforated necrotizing enterocolitis in preterm infants.

The cases with anatomopathological findings which were not clinically suspected and had a significant implication for genetic counseling (class I.B) included congenital hemochromatosis, visceral myopathy, osteochondrodysplasia, and Beckwith-Wiedemann syndrome.

The cases whose autopsy findings would not have modified management (class II) included mild to moderate intracerebral hemorrhage, kernicterus, pyoventriculitis (associated with sepsis in other sites), and mild necrotizing tracheobronchitis.

In the group of patients whose diagnosis, whether related or not to the main disease process, was a contributory cause of death (class III) included pulmonary hemorrhage, severe necrotizing tracheobronchitis, myocardial infarction, grade IV intracerebral hemorrhage, and a case of intussusception with acute peritonitis.

\section{DISCUSSION}

The rate of autopsies in the 9-year period was $59.5 \%$. The rate published in different developed countries ranges between $52 \%$ and $67 \%^{1,2,6}$ whereas that in Argentina is below 15\%.,4

There is wide consensus regarding the contributions made by neonatal autopsy to confirm clinical diagnosis and identify diseases and congenital malformations, ${ }^{7-9}$ as well as its addition to medical education, ${ }^{10}$ and its medical legal worth.

TABLE 1. Classification developed by Goldman et al. as modified by Kumar et al.

I. A A diagnosis that had it been detected before death, would probably have led to a change in management resulting in cure or survival.

I. B A diagnosis made based on the autopsy with significant implications for genetic counseling.

II A diagnosis that had it been detected before death, would probably not have led to a change in management resulting in cure or survival for the following reasons:

- No appropriate therapy was available at the time.

- Appropriate therapy was given even though the diagnosis was unknown at the time.

- The patient suffered an acute cardiopulmonary arrest that was appropriately managed but did not survive for definite management.

- $\quad$ The patient did not recover from cardiopulmonary arrest.

III A diagnosis that was a contributory cause of death and that may or may not have been related to the main disease process.

IV A diagnosis unrelated to disease course and that may or may not have affected the eventual prognosis of the patient.

V Complete concordance between clinical diagnosis and autopsy findings. 
Dhar et al. ${ }^{11}$ and Faye-Petersen et al. ${ }^{12}$ analyzed the influence of autopsy to counsel parents and established that counseling would have been different to that provided in $26 \%$ of cases if only clinical data had been available.

Our results are consistent with those of these studies given that, also in $26 \%$ of cases, autopsy findings contributed to provide counseling for future pregnancies.

As to concordance between the clinical diagnosis and autopsy findings, data from this study are similar to those published by Cohen ${ }^{3}$ in Argentina, who used the same classification in 100 autopsies (36 neonates and 64 infants). Whereas in our study concordance was complete in $25 \%$ of cases (class V) and autopsies provided new information in $75 \%$, the study conducted by Cohen showed a 32\% complete concordance and new information was revealed in $68 \%$ of cases.

A recent systematic review showed that out of 1757 neonatal and pediatric autopsies, diagnostic errors (class I) accounted for $4.5 \%$ of cases whereas in our study it was $6.6 \% .^{13}$

The marked decline in autopsies worldwide is a cause for concern, especially in Argentina. Publications of the Argentine Society of Pediatrics reflect the size of this problem in an editorial comment titled Going back to autopsy or continuing to ignore the truth. ${ }^{14}$ A recent publication by Hospital de Niños Ricardo Gutiérrez (Buenos Aires) reports a similar situation and expresses concern on this situation and its uncertain future. ${ }^{4}$

In this regard, and facing the decline in the rate of autopsies, Florencio Escardó, M.D. ${ }^{15}$ predicted in a pediatric publication from the 1980s titled The ethical sense of autopsies: "Autopsies should be performed systematically, not only as a duty to knowledge but also as an obligation towards patients and their families."

Highly motivated neonatologists, the availability of pathologists experienced in the performance of autopsies in a timely manner to allow for reasonable burial planning, the fact that costs were covered by health insurance companies, and the characteristics of the population of our hospital may account for the high rate of autopsies observed in this study.

This study poses certain limitations, for example, its retrospective nature and data collection based on medical records.

\section{CONCLUSION}

The rate of autopsies was $59.5 \%$. Results of pathological and clinical correlation, its influence on family counseling regarding future pregnancies, and autopsy contributions to medical knowledge confirm the relevance of performing autopsies systematically in the field of neonatology.

\section{REFERENCES}

1. Brodlie M, Laing IA, Keeling JW, et al. Ten years of neonatal autopsies in tertiary referral centre: retrospective study. BMJ 2002;324(7340):761-3.

2. Khong TY. Falling neonatal autopsy rates. BMJ 2002;324(7340):749-50.

3. Cohen M, Drut R. La autopsia en pediatría. Diagnóstico de situación en un hospital de pediatría de referencia. Arch Argent Pediatr 2003;101(3):166-70.

4. Farías S. La autopsia: presente.... ¿y futuro? Análisis estadístico de las autopsias realizadas en el Hospital de Niños "Ricardo Gutiérrez", entre enero 1980 y diciembre 2009. Rev Hosp Niños B Aires 2012;54(244):4-14.

5. Goldman L, Sayson R, Robbins S, et al. The value of the autopsy in three medical eras. $N$ Engl J Med 1983;308(17):1000-5.

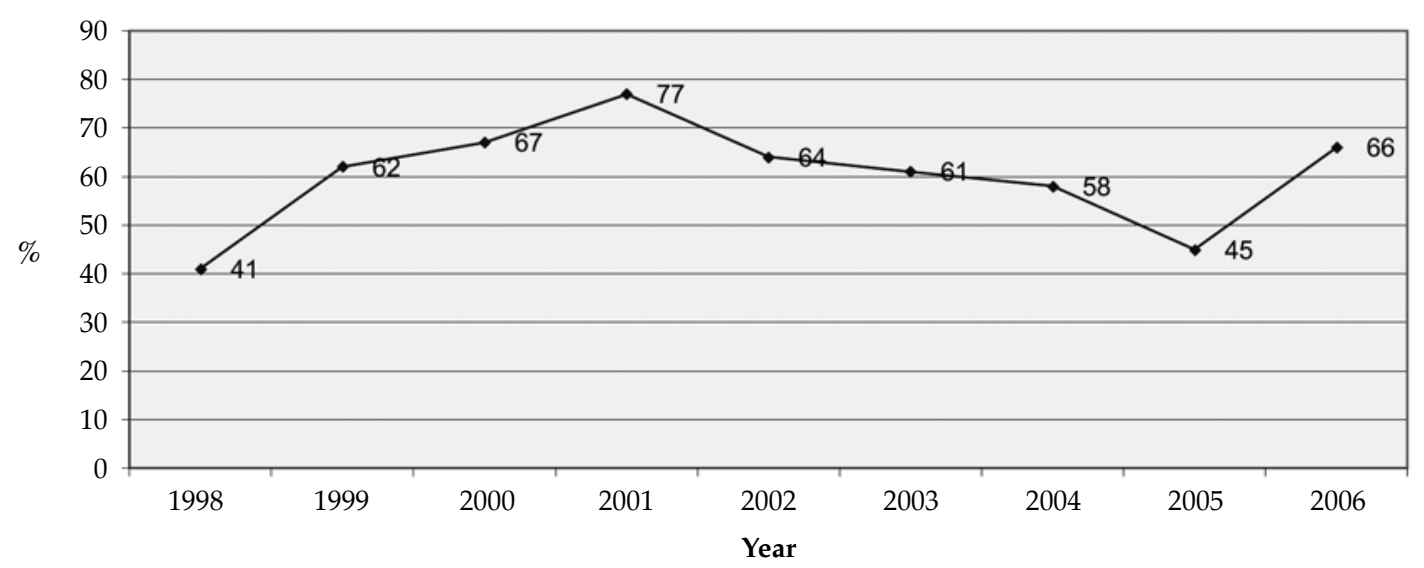


6. Kumar P, Angst DB, Taxy J, et al. Neonatal autopsies: a 10year experience. Arch Pediatr Adolesc Med 2000;154(1):38-42.

7. Swinton $\mathrm{CH}$, Weiner J, Okah FA. The neonatal autopsy: can it be revived? Am J Perinatol 2013;30(9):739-44.

8. Hickey L, Murphy A, Devaney D, etal. The value of neonatal autopsy. Neonatology 2012;101(1):68-73.

9. Rose C, Evans M, Tooley J. Falling rates of perinatal postmortem examination: are we to blame? Arch Dis Child Fetal Neonatal Ed 2006;91(6):F465.

10. Burton JL, Underwood J. Clinical, educational, and epidemiological value of autopsy. Lancet 2007; 369(9571):1471-80.
11. Dhar V, Perlman M, Vilela MI, et al. Autopsy in a neonatal intensive care unit: utilization patterns and associations of clinicopathologic discordances. J Pediatr 1998;132(1):75-9.

12. Faye-Petersen OM, Guinn DA, Wenstrom KD. Value of perinatal autopsy. Obstet Gynecol 1999;94(6):915-20.

13. Custer JW, Winters BD, Goode V, et al. Diagnostic errors in the Pediatrics and Neonatal ICU: A Systematic Review. Pediatr Crit Care Med 2015;16(1):29-36.

14. Schnitzler E. Volver a la autopsia o seguir ignorando la verdad. Arch Argent Pediatr 2003;101(3):163-4.

15. EscardóF. Sentidoético dela autopsia. Boletín de la IICátedra de Pediatría 1964;2.

\title{
Serum prolactin levels in atopic dermatitis and the relationship with disease severity
}

\author{
Burcu Tuğrul Ayanoğlu, M.D. ${ }^{a}$, Özgül Muştu Koryürek, M.D. ${ }^{a}$, Songül Yıldırım Başkara, M.D. ${ }^{b}$
}

\begin{abstract}
Background. Prolactin performs as a neuroendocrine modulator of skin epithelial cell proliferation and the skin immune system. Objective. The aim was to assess the serum prolactin levels in patients with atopic dermatitis and the relationship with disease severity.

Methods. The study was performed on 46 patients with atopic dermatitis and 100 healthy controls aged between 0.5 years and 19.5 years. The diagnosis of atopic dermatitis was based on clinical findings and the severity of the disease was documented. Venous blood sampling was performed in order to measure prolactin levels.

Results. Prolactin levels in atopic dermatitis were not different from controls and there was no relationship between the severity of atopic dermatitis and serum prolactin levels. Prolactin may not have a role in the pathogenesis of atopic dermatitis. Further studies with larger sample sizes and measurement of prolactin levels in the skin may help to understand the role of prolactin in the pathogenesis of atopic dermatitis.

Keywords: Atopic dermatitis, prolactin, SCORAD index, child.
\end{abstract}

http:/ / dx.doi.org/10.5546/ aap.2017.eng.493

To cite: Tuğrul Ayanoğlu B, Muştu Koryürek Ö, Yıldırım Başkara S. Serum prolactin levels in atopic dermatitis and the relationship with disease severity. Argent Pediatr 2017;115(5):493-496.

a. Aksaray University, Aksaray Training and Research Hospital, Department of Dermatology and Venereology. Aksaray, Turkey.

b. Aksaray University, Aksaray Training and Research Hospital, Department of Pediatrics. Aksaray, Turkey.

E-mail address:

Burcu Tuğrul Ayanoğlu, M.D.: burcutugrul@yahoo.com

Funding: None.

Conflict of interest: None.

Received: 12-20-2016

Accepted: 5-16-2017

\section{INTRODUCTION}

Atopic dermatitis (AD) is a chronically relapsing inflammatory skin disease associated with complex interactions among susceptibility genes, the host's environment, defects in skin barrier function and systemic and local immunologic responses. The disease is characterized by eczematous skin lesions and intense pruritus that often occur in early childhood but can also start or persist in adulthood. ${ }^{1}$ Scoring systems have been developed for use in trials.

Prolactin (PRL) is a polypeptidic neuropeptide produced by lactotroph cells in the anterior pituitary gland and is well known for its lactogenic and mammotrophic effects. It has been hypothesized that forming a 'prolactincircuit' between the central nervous system and the skin, prolactin performs as a neuroendocrine modulator of skin epithelial cell proliferation and of the skin immune system. PRL plays an important role in the immune reactions and exerts a proliferative effect on human keratinocytes by binding specific sites. ${ }^{4}$ Previous studies have assessed the association of PRL levels with psoriasis as a hyperproliferative cutaneous disease of multifactorial etiology; however, the results seem contradictory. Epidermal hyperproliferation that is observed in both psoriasis and atopic dermatitis and its underlying mechanisms are not completely understood by now. ${ }^{8}$

Only some rare information is available on the 